\title{
Decision Support Model based on Fuzzy-Logic Conception in Determining Region - "Ojek Online" Transporter Appropriateness
}

\author{
Ditdit Nugeraha Utama ${ }^{1}$, Shofiya Arrahmani ${ }^{2}$, Isna Wirahmadayanti ${ }^{2}$, Ashifa Ayuningtias ${ }^{2}$ \\ ${ }^{1}$ Computer Science Department, BINUS Graduate Program - Master of Computer Science, Bina Nusantara \\ University, Jakarta, Indonesia 11480, ditdit.utama@binus.edu \\ ${ }^{2}$ Information System, UIN Syarif Hidayatullah, Jakarta, Indonesia
}

\begin{abstract}
"Ojek Online" (OJOL) is an online based public transportation mode functioning a motorcycle to do the operational activity. By using a mobile application, customers are easily able to find a public transporter OJOL which directly picks-up and brings them from one place to other specific place. However, properness of implementing such an OJOL is one issue. Is proper that OJOL implemented in one region? Thru using a method fuzzy logic, the decision support model (DSM) for measuring the appropriateness of OJOL implementation in one region in Indonesia was constructed scientifically. The model was applied to measure the properness level OJOL implementation in Depok city in Indonesia.
\end{abstract}

Key words: ojek online, fuzzy logic, decision support model, Indonesia.

\section{INTRODUCTION}

The large number of vehicles and also development of the road applied slowly are two causes of congestion. Congestion is a decrease in the smooth flow of traffic on existing roads, and greatly affects the perpetrators of the trip, both using public transport and private transportation. It has an impact on inconvenience and increase travel time for travelers [1]. Motorcycles are the first choice for effective and efficient transportation. In this globalization era, there are several transactions using an online application that can be used to order a motorcycle transporter service online to get to the destination [2].

Regarding this online transportation, it is regulated in Permenhub No. 32 of 2016 (regulation coming from Transportation Department of Indonesian Republic) concerning implementation of transportation of people with public motorcycle not in route. The reason for researchers chose the online motorcycle transporters as a solution in this study is because online motorcycle transporter have many advantages; such as in terms of price, safety, service and convenience in ordering online motorcycle transporter.

Ojek, a traditional motorcycle transporter in Indonesia. It provides an alternative transportation solution in the midst of crowded vehicles: It can be fast and can reach places that might not be reached by cars or other public vehicles. If a conventional motorcycle transporter can usually only be found at the specific area, online motorcycle transporter can be ordered whenever and anywhere customers need. They only operate an application on the smartphone and then they picked-up without fees.

There are a lot of online motorcycle transporters in a certain area, but it does not necessarily mean that they are suitable in that area. This study aims to help online motorcycle transporter companies and the government to determine the suitability of online motorcycle public transporter (ojek online, or called OJOL) operating in certain areas based on four parameters (i.e. number of residents, population income, area, and number of private vehicles). The main method used in this study is the fuzzy-logic method. The data of this research were obtained through secondary data, it is available data collected by other parties and then collected by researchers as supporting data for the study. From this research it is expected to construct a decision support model (DSM) providing decisions to determine the suitability of online motorcycle transportation one area. It affects.

\section{RESEARCH METHODOLOGY}

\subsection{Research Stages}

There are three stages (Figure 1) operated to conduct this study methodologically; model and case analysis, model design, and model construction. In the first stage, model and case analysis, the comprehensive perspective of model constructed was acquired. Here, the common problem practically occurs was successfully defined. It is a problem of difficulty for a local government to assess the properness of 
OJOL implementation. DSM is hypothetically able to solve such a specific problem.

The model design was conducted in the second stage. In this stage, the UML tools (e.g. class diagram, component diagram, etc.) were operated to design it. Those tools are main tool of object oriented model design [3]. Thru the design, the constructed model is able to be comprehended well. Then, finally the model was constructed. The proposed decision can be reached by running the constructed model. It could be operated as scientific-proposed decision to be taken by a local government decision maker.

The fuzzy-logic method mainly also used in conducting both stages number one and two. Indeed, it was first introduced by Professor Lotfi A. Zadeh, a professor at the University of California, who was the originator and marketer of ideas about how to process uncertainty processing or management mechanisms which became known as fuzzy logic [4] also ever operated by [5]. Fuzzy set is a grouping of things based on language variables (linguistic variable), which is expressed by the membership function, in the universe U. Membership of a value in the set is expressed with the degree of membership whose value is between 0.0 to 1.0 . In doing fuzzification, we need a membership function (membership function). This membership function is a representation of language variables mapped to the value of the truth (degree of the truth) [6].

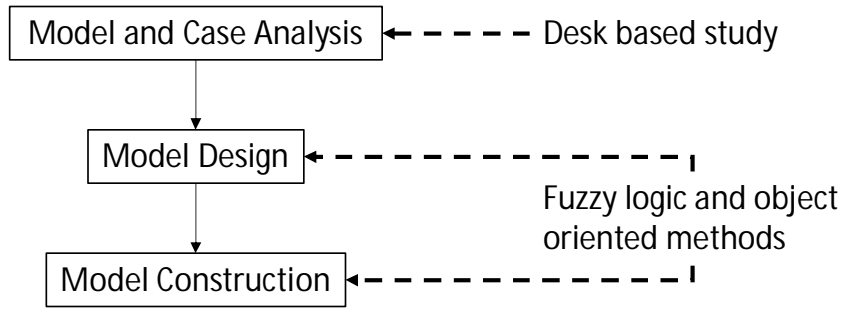

Figure 1: Stages of Study

\subsection{Data Collection}

Secondary data is data obtained/collected and put together by previous studies or published by various other agencies. The source of this research data was obtained from the official statistics center agency for Indonesia (BPS) website (https://www.bps.go.id/) and for regional sample data obtained from the official city of Depok city (http://www.depok.go.id). Secondary data to support this research were also obtained from books, study reviews and literature reviews regarding online transportation, traffic jams and about fuzzy-logic methods.

\subsection{Parameters Involved}

In this study, four parameters that support to determine a decision solver are operated; total population, area, number of private vehicles, and population income. The parameters in this study come from the analysis of the author and various journals that discuss online transportation, especially online motorcycle transporter. These parameters are the first population, if in an area has a large population means more and more individual needs to support their activities. This is where the role of the online motorcycle transporter as a support of these activities. Because of the large number of population and various kinds, the number of online motorcycle transporters needed is also increasing.

The second parameter is the area. The area size affects the distance and what transportation is used to reach the location such as to the office, school, market, and others. The wider an area, the farther the distance that must be traveled and the higher the need for transportation to carry out these activities [7].

The third parameter is the number of private vehicles. The more number of private vehicles in an area, the higher the level of congestion in that region. Thus, individuals will really need alternative transportation such as online motorcycle transporters to overcome these problems.

And the last parameter is population income. It is undeniable that the higher the income, the better the type of work is assumed and the more effective transportation needs to arrive on time at work. Usually at rush hour (i.e. morning and evening) is a time when traffic conditions are flooded by various vehicles, causing congestion. Of course, for people who have to go to work during rush hour, they will not want to linger in traffic for a long time, so the role of online motorcycle transporter is very important in this condition.

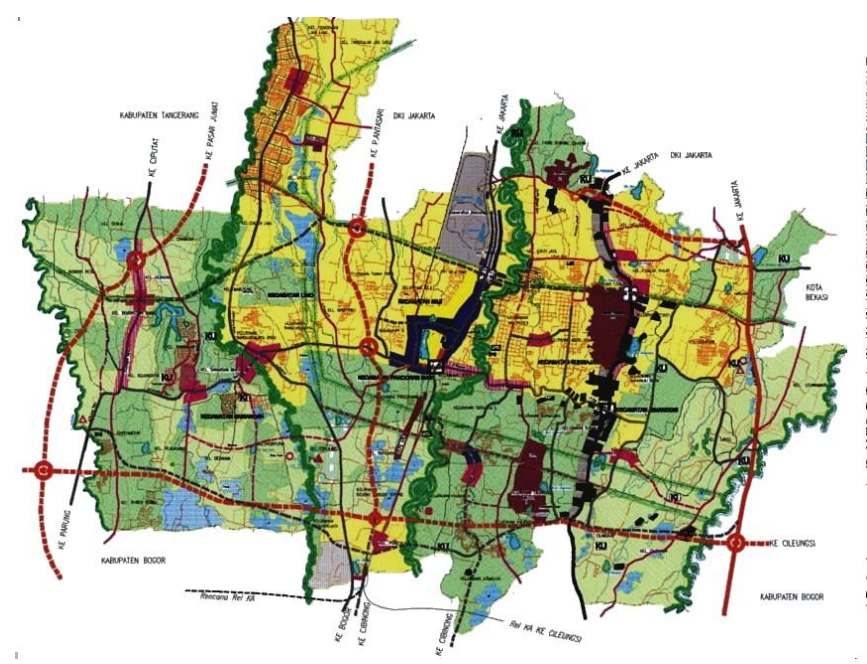

Figure 2: Map of Depok City

Based on data obtained from the website http://www.depok.go.id the city of Depok with an area of only $200.29 \mathrm{~km} 2$, in fact has a population of $1,588,582$ people with 923,000 private vehicles (please see Figure 2). The average population income is Rp. 6,300,000, which shows that the average income of Depok residents is in the middle and upper 
Ditdit Nugeraha Utama et al., International Journal of Emerging Trends in Engineering Research, 8(5), May 2020, 1523- 1528

classes and is categorized as a city with a dense population with a number of private vehicles that are also dense but only has a relatively small area. This briefly illustrates that the city of Depok is a city that is very stuck. Many factors cause traffic jams in the city of Depok. High population growth and lack of road infrastructure development are the main contributors to traffic congestion.

\section{CONSTRUCTED MODEL}

\subsection{High Level Configuration of Constructed Model}

The constructed model consists of two main classes; Public Transporter and Region. Other classes are supporting parts that are able to model successfully run. They are classes Decision and fuzzy logic, with their derivative classes. All parameters involved in the model defined in class Region and its derivative classes. Conceptually, the high level of the constructed model configuration is depicted in Figure 3 via class diagram ever functioned also by [8].

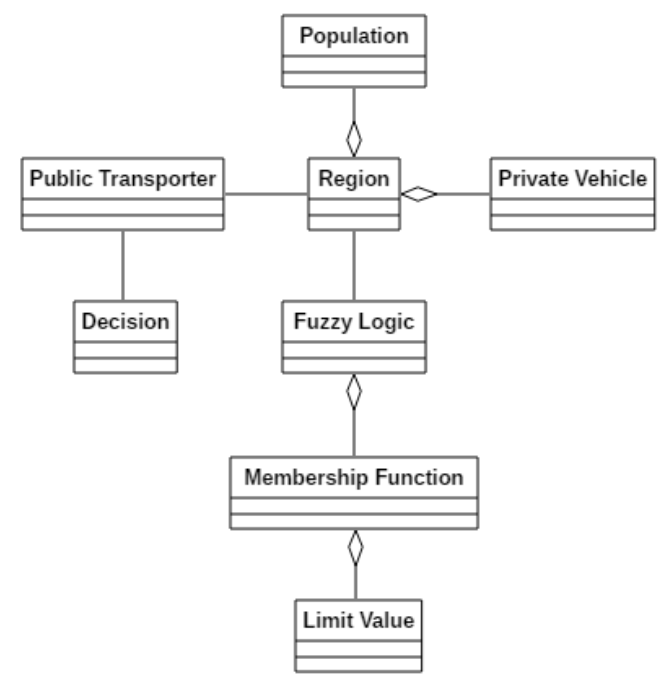

Figure 3: Class Diagram of the Constructed Model

Furthermore, there are four components in the model; they are Public Transporter, Region, Fuzzy Logic, and Decision. The component diagram of the constructed model is described in Figure 4. The component itself is an individual function (or sub-model) that is able to be executed personally. Components Public Transporter and Region deliver data value of parameters. Then, the value are measured in component Fuzzy Logic to produce a proposed decision regarding properness value of public transporter implementation in one region.

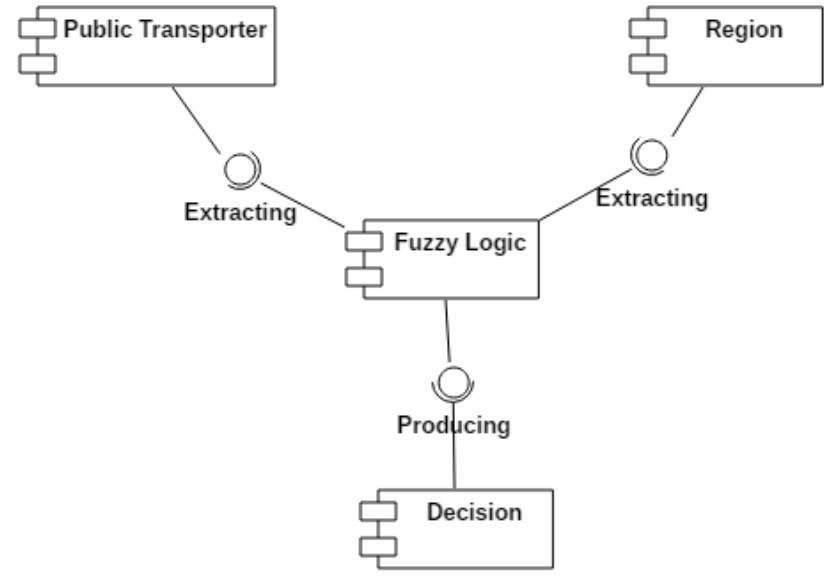

Figure 4: Component Diagram of the Constructed Model

\subsection{Fuzzy-Logic Method and Assessments}

Table 1 until 4 show respectively the value range of parameters' involved for parameters population, area, population income, and number of private vehicle. Also, they described the linguistic variable of each value.

Table 1: Value Range and Linguistic Variable for Parameter Population

\begin{tabular}{|r|l|}
\hline \multicolumn{1}{|c|}{ Range } & Linguistic Variable \\
\hline$<300,000$ & Very Low \\
\hline $25,000-1,200,000$ & Low \\
\hline $500,000-2,000,000$ & Medium \\
\hline $1,400,000-3,000,000$ & High \\
\hline$>2,500,000$ & Very High \\
\hline
\end{tabular}

Table 2: Value Range and Linguistic Variable for Parameter Area

\begin{tabular}{|r|l|}
\hline \multicolumn{1}{|c|}{ Range } & Linguistic Variable \\
\hline$<500$ & Very Small \\
\hline $50-2,500$ & Small \\
\hline $1,000-4,500$ & Medium \\
\hline $3,000-7,000$ & Big \\
\hline$>5,000$ & Very Big \\
\hline
\end{tabular}

Table 3: Value Range and Linguistic Variable for Parameter Population Income

\begin{tabular}{|r|l|}
\hline \multicolumn{1}{|c|}{ Range } & Linguistic Variable \\
\hline$<2,000,000$ & Low \\
\hline $1,000,000-6,000,000$ & Medium Low \\
\hline $5,000,000-10,000,000$ & Medium High \\
\hline$>8,000,000$ & High \\
\hline
\end{tabular}

Table 4: Value Range and Linguistic Variable for Parameter Private Vehicle Number

\begin{tabular}{|r|l|}
\hline \multicolumn{1}{|c|}{ Range } & Linguistic Variable \\
\hline$<600,000$ & Few Vehicle \\
\hline $300,000-2,000,000$ & Moderate \\
\hline $1,000,000-3,000,000$ & High Moderate \\
\hline$>3,000,000$ & Many \\
\hline
\end{tabular}


For each parameter based on the highest, lowest, and national average data regarding population, area, income and number of private vehicles from the BPS website and Depok city website. In Table 5, empirical data was showed; where Pr. is representing parameters, $\mathrm{P}$ is population, $\mathrm{A}$ is area, $\mathrm{PN}$ presents a private vehicle number, and PI symbolizes a population income.

Table 5: Empirical Data of Depok City

\begin{tabular}{|l|r|r|r|r|}
\hline Pr. & \multicolumn{1}{|c|}{ Lowest } & \multicolumn{1}{c|}{ Highest } & \multicolumn{1}{c|}{ Empirical Data } & \multicolumn{1}{c|}{ Unit } \\
\hline P & $300,000.00$ & $2,500,000.00$ & $1,588,582.00$ & people \\
\hline A & 500.00 & $5,000.00$ & 200.29 & $\mathrm{Km}^{2}$ \\
\hline PN & $600,000.00$ & $3,000,000.00$ & $923,000.00$ & unit \\
\hline PI & $2,000,000.00$ & $8,000,000.00$ & $6,300,000.00$ & Rupiah \\
\hline
\end{tabular}

Based on [6], in doing fuzzy logic process, we need a number of things; first doing fuzzification (i.e. determining linguistic variables, determining membership functions to calculate the fuzzy value of each variable), operating fuzzy rules, and then doing defuzzification. According to [9], membership function is the degree to which the value of crisp with the membership function (from 0 to 1 ), also refers to the level of membership, truth value, or fuzzy input.

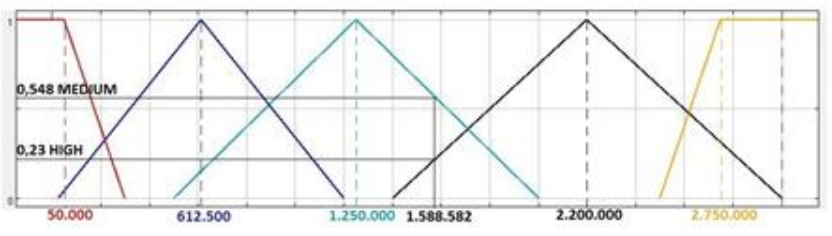

Figure 5: Membership Function for Population

In Figure 5, parameter Population can be defined as having five linguistic variables, with each of them illustrated on a five-point scale. These variables respectively are very low with a membership scale $(<300,000)$, low with a membership scale $(50,000,612,500,1,250,000)$, medium with a membership scale $(612,500,1,250,000,2,000,000)$, high with a membership scale $(1,400,000,2,200,000,3,000,000)$, and very high with a membership scale $(>2,500,000)$ people.

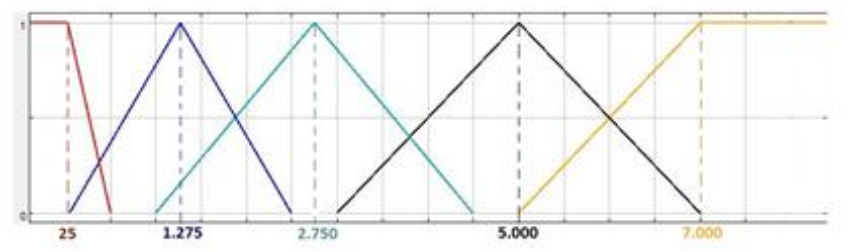

Figure 6: Membership Function for Area

In Figure 6, parameter Area can be defined as having five linguistic variables, with each of them illustrated on a five-point scale. These variables correspondingly are very small with membership scale $(<500)$, small with membership scale $(25,1,275,2,500)$, medium with membership scale $(1,000,2,750,4,500)$, big with membership scale $(3,000$, $5,000,7,000)$, and very big with a membership scale $(>5,000)$ $\mathrm{km} 2$.

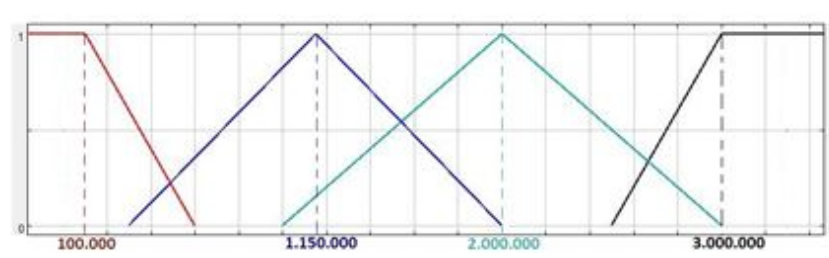

Figure 7: Membership Function for Private Vehicles Number

In Figure 7, parameter number of private vehicles can be defined as having four linguistic variables, with each of them depicted on a four-point scale. These variables individually are few with membership scale $(<600)$, moderate with membership scale $(300,000,1,150,000,2,000,000)$, medium with membership scale $(1,000,000,2,000,000,3,000,000)$, and big with scale membership (> 3,000,000) units.

In Figure 8, parameter population income can be defined as having four linguistic variables, with each of them depicted on a four point scale. These variables respectively are low with a membership scale $(<2,000,000)$, middle-low with a membership scale $(1,000,000,4,000,000,7,000,000)$, middle-high with a membership scale $(4,000,000,7,000,000$, $10,000,000)$, and high $(>8,000,000)$ rupiah.

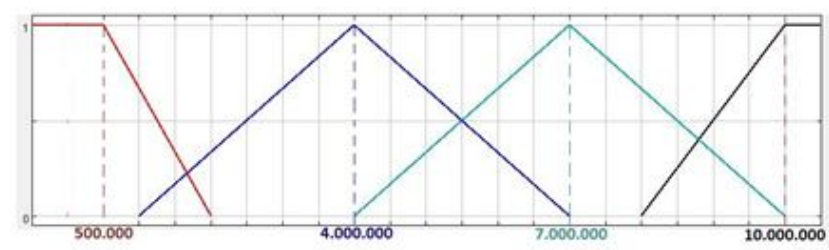

Figure 8: Membership Function for Population Income

The data is then included in the fuzzy-logic calculation. For calculating the degree of truth, linear interpolation approach is operated. For example, based on the data, the population of Depok city is $1,588,582$ people; the value of fuzzy obtained are 0.55 medium and 0.23 high. It means, the parameter population has fuzzy value 0.55 medium and 0.23 high. The illustration of calculation is presented in Figure 9. Also, the illustration of calculation of fuzzy value for each other parameter area, private vehicle number, and population income respectively depicted in Figure 10 until 12.

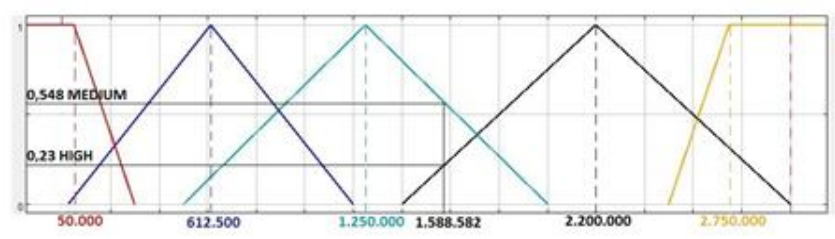

Figure 9: Membership Function for Population Number 
Ditdit Nugeraha Utama et al., International Journal of Emerging Trends in Engineering Research, 8(5), May 2020, 1523- 1528

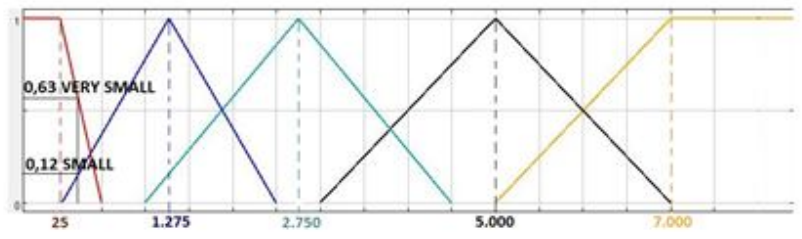

Figure 10: Membership Function for Area

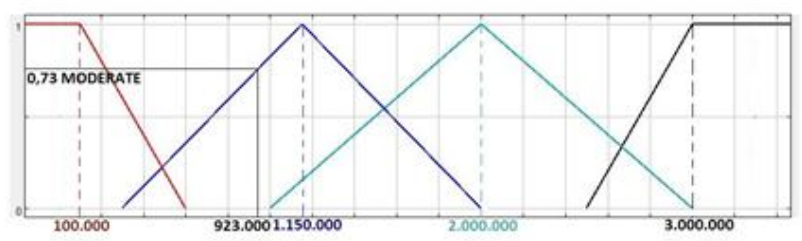

Figure 11: Membership Function for Private Vehicle Number

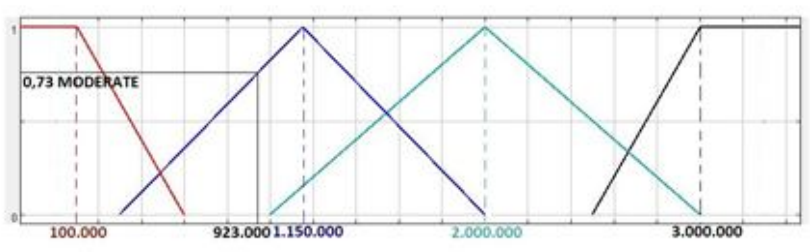

Figure 12: Membership Function for Population Income

Furthermore, in the constructed model, 390 fuzzy rules are operated. They used to determine status match or not match for implementing OJOL in this administrative city Depok. The examples of the fuzzy rule are represented in Code 1 , and the membership function of final decision is represented in Figure 13. With the membership function in Figure 13, the decision is match and not match. Based on Code2, and calculation of crisp output (CO) based on equation (1) (where $F V_{i}$ is the $\bar{t}$ th fuzzy value and $C O G_{i}$ presents the $i$ th center of gravity); the result shows that $\mathrm{CO}$ is $60 \%$, it means that OJOL is scientifically $60 \%$ match and possibly to be implemented.

Code 1: Fuzzy Rules

If $($ Population $=$ Very Low $)$ AND $($ Area $=$ Very Small $)$ AND (Individual Vehicles Number $=$ Few) AND (Population Income $=$ Low $)$ THEN $($ OJOL $=$ Not Match $)$

If $($ Population $=$ Very Low $)$ AND $($ Area $=$ Very Small $)$ AND (Individual Vehicles Number $=$ Moderate) AND (Population Income $=$ Low $)$ THEN $(\mathrm{OJOL}=$ Not Match $)$

If $($ Population $=$ Very High) AND (Area $=$ Very Big $)$ AND (Individual Vehicles Number $=$ High Moderate $)$ AND $($ Population Income $=$ High $)$ THEN $(\mathrm{OJOL}=$ Match $)$

If $($ Population $=$ Very High $)$ AND $($ Area $=$ Very Big $)$ AND (Individual Vehicles Number $=$ Many) AND (Population Income $=$ High $)$ THEN $(\mathrm{OJOL}=$ Match $)$

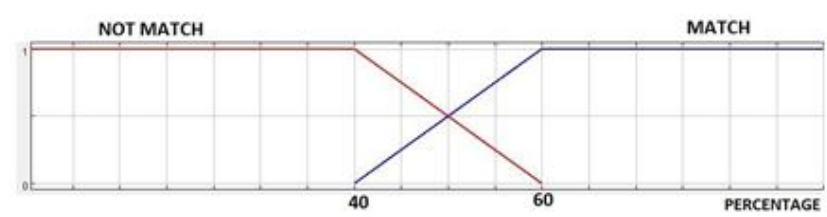

Figure 13: Membership Function for Decision

Code 2. Implementation of Data in Fuzzy Rules

IF (Population $=0.548$ Medium) AND (Area $=0.63$ Very Small) AND (Private Vehicle Number $=0.73$ Moderate) AND (Population Income $=0.76$ Middle-High) THEN (OJOL is 0.548 MATCH) (based on rule number 262)

IF (Population $=0.23$ High) AND (Area $=0.12$ Small $)$ AND (Private Vehicle Number $=0.73$ Moderate) AND (Population Income $=0.76$ Middle-High) THEN (OJOL is 0.12) MATCH (based on rule number 202)

$$
C O=\frac{\sum_{i=1}^{n}\left(F v_{i} \times \cos _{i}\right]}{\sum_{i=1}^{L} 2 V_{i}}
$$

\subsection{Dashboard of Model}

Many of us to more easily read reports, analyze data and predict future data tend to use images instead of looking at numbers and tables that are large / large and complex. Our brain tends to see images and colors more than rows of numbers. Dashboard or commonly called digital dashboard is a display panel created by a computer software with the aim of displaying information that is easy to read.

Dashboard is one of the solutions for data presentation and visualization. Dashboard is an information system interface model analogous to a car dashboard that is easy to learn. Dashboards can communicate important information quickly. Every user needs access to information that is well structured and clear. Therefore an effective dashboard design becomes very important. A good design for the presentation and visualization of data will provide clarity about the important information conveyed to users. With a good design, a dashboard created will be able to assist users in identifying trends, patterns, and anomalies in the data so that it can ultimately assist in effective decision making.

The constructed model dashboard is depicted clearly in Figure 14. Thru the dashboard, the decision maker could manage all properness value of administrative city regarding the implementation of OJOL in its area. 


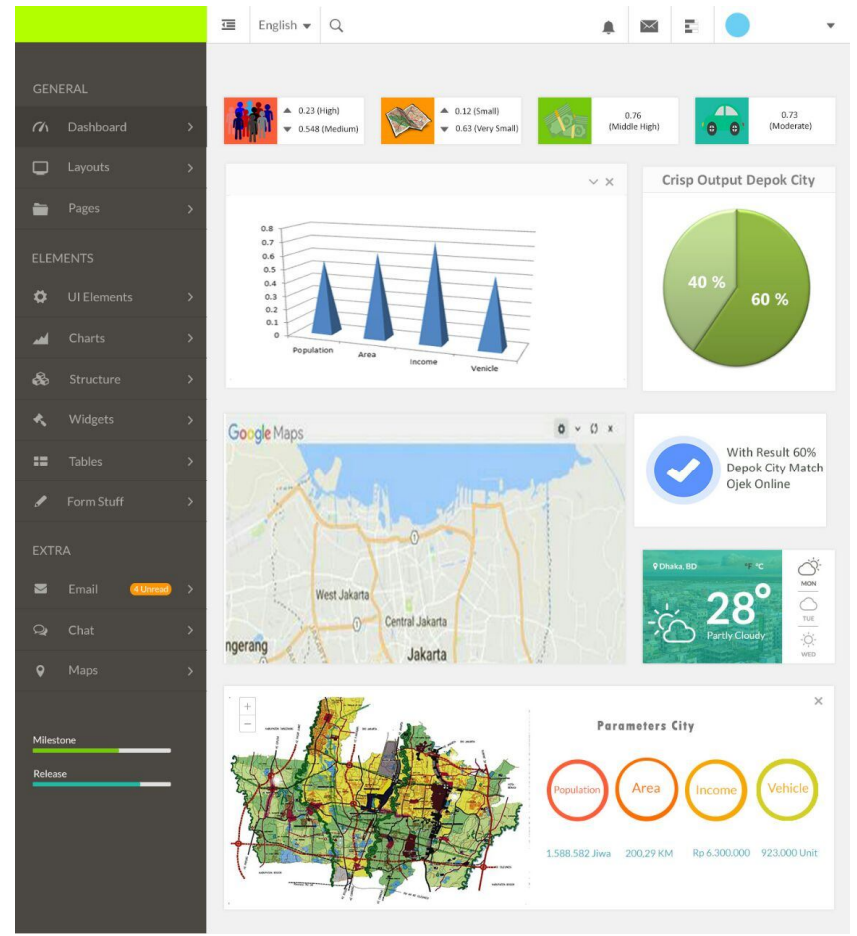

Figure 14: The Constructed Model Dashboard

\section{CONCLUSION AND FURTHER WORKS}

Decision support model based on fuzzy logic was successfully developed. It could help the decision maker (a local government, in this case) to evaluate that OJOL is proper or not to be implemented in his/her administrative region. The model has been tested theoretically by using region/city Depok's empirical data. The model suggested that OJOL is $60 \%$ proper to be realized in the city Depok.

Indeed, the constructed model is open to evaluate the implementation properness for other public transporter. Where, the generic characteristic of the model was portrayed via class and component diagrams. Moreover, the identification of other parameters is methodically required. It is going to enrich the model. This is still open to do as a further work.

\section{ACKNOWLEDGEMENT}

We would like to thank BINUS University who has supported our works, particularly BINUS graduate program, Master of Computer Science.

\section{REFERENCES}

1. M. Margareth, P. J. C. Franklin, and F. Warouw. Studi Kemacetan Lalu Lintas di Pusat Kota Ratahan, SPASIAL: Perecanaan Wilayah dan Kota, vol. 2, no. 2, pp. 90-97, 2015.
2. M. Lowry. Online public deliberation for a regional transportation, Transportation, vol. 37, no. 1, pp. 39-58, 2009. https://doi.org/10.1007/s11116-009-9219-7

3. G. Booch, R. Maksimchuk, M. Engle, J. Conallen, K. Houston, and B. Young. Object-oriented analysis and design with application, Pearson Education, 2009.

4. L. A. Zadeh. Fuzzy Sets As A Basis For A Theory Of Possibility, Fuzzy Sets And Systems, vol. 100, no. S-1, pp. 9-34, 1999. https://doi.org/10.1016/S0165-0114(99)80004-9

5. D. N. Utama and U. Taryana. Fuzzy logic for simply prioritizing information in academic information system, International Journal of Mechanical Engineering and Technology, vol. 10, no. 2, pp. 1594-1602, 2019.

6. D. N. Utama. Sistem penunjang keputusan: Filosofi, teori, dan implementasi, Yogyakarta: Garudhawaca, 2017.

7. T. Litman and D. Burwell. Issues in sustainable transportation, International Journal of Global Environment Issues, vol. 6, no. 4, pp. 331-347, 2006. https://doi.org/10.1504/IJGENVI.2006.010889

8. D. N. Utama, F. A, Zaki, I. J. Munjeri, and N. Putri. FWFA optimization based decision support system for road traffic engineering, in Proc. International Conference on Computing and Applied Informatics, Indonesia, Medan, 2016. https://doi.org/10.1088/1742-6596/801/1/012016

9. Marimin. Teori dan aplikasi sistem pakar dalam teknologi manajerial (1st ed.), Bogor: IPB Press., 2007. 